\title{
A METHOD OF BITE FORCE MEASUREMENT IN PRIMATES
}

\author{
Paul C. Dechow and David S. Carlson \\ Department of Anatomy and Cell Biology, and Center for Human Growth and Development. \\ The University of Michigan, Ann Arbor, MI 48109, U.S.A.
}

\begin{abstract}
A bite force transducer consisting of two differential strain beams with four strain gages in a full bridge configuration was modified for measuring occlusal forces in rhesus monkeys. A procedure of muscle stimulation $(20-50 \mathrm{~V}, 60 \mathrm{~Hz}$, and $0.8 \mathrm{~ms}$ duration) produced maximal unilateral masticatory muscle contraction when stimulating electrodes were placed in the masseter muscle. Tests of this procedure revealed reproducible results and a potential for use in studies of the force of isometric contraction of the masticatory muscles in normal and experimentally altered macaques and other primates.
\end{abstract}

\section{INTRODUCTION}

Bite force measurement has been used as a noninvasive method for assessing properties of the craniofacial complex including craniofacial biomechanics (Fields $e t$ al., 1982; Proffit et al., 1982; Ringqvist, 1973b; Throckmorton et al., 1980) and the strength (Black, 1895; Brekhaus et al., 1941; DeBoever et al., 1978; Dechow and Carison, 1982a; Howell and Brudevold, 1950; Nyquist and Owall, 1968; Pruim, 1979; Pruim et al., 1980; Ringqvist, 1973a: Robins, 1977; Worner, 1939; Worner and Anderson, 1944), electrical activity (Garrett et al., 1969; Palla and Ash, 1981) and length-tension relationships (Dechow and Carlson, 1982b: Manns et al., 1979; Nordstrom and Yemm, 1974; Thexton and Hiiemae, 1975) of the muscles of mastication. Additionally, bite force has been used to indicate alterations in masticatory function with changes in vertical dimension (Boos, 1940; Boucher et al., 1959; Tueller, 1969), muscle training (Linderholm et al., 1971: Yurkstas, 1953), muscle position (Dechow et al., 1983), dentures (Brudevold, 1951; DeHernandez and Bodine, 1969; Frechette, 1955; Manly and Vinton, 1951; Tarbet et al., 1981); tooth loss (Atkinson and Ralph, 1973: Helkimo et al., 1977), malocclusion (Garner and Kotwal, 1973: Garrett et al., 1969; Johnson and Hatfield, 1917), and functional disturbances (Helkimo et al., 1975; Helkimo and Ingervall, 1978; Lingqvist and Ringqvist, 1973; Molin, 1972). Many human studies have been confounded by the psychological component of bite force (Marklund and Wennström, 1972; Wennström, 1971, 1972). This is not a problem in animal studies where bite force can be generated by electrical stimulation of the masticatory muscles of anesthetized animals (Dechow and Carlson, 1982a; b; Nordstrom and Yemm, 1974; Robins, 1977; Thexton and Hiiemae, 1975). However, it can be inferred that bite force produced by muscle stimulation would not

Received January 1983; in revised form March 1983. be influenced by sensory feedback from periodontal mechanoreceptors. Thus, it can be argued that studies of stimulated bite force record simply the strength of the masticatory muscles as mediated through the biomechanics of the jaws rather than the more complex phenomenon of voluntary bite force that would be additionally mediated by neurophysiological control.

This report describes a method of muscle stimulation and bite force measurement in use in our laboratory for long and short term studies of changes in craniofacial biomechanics and in the physiological properties of the masticatory muscles of rhesus monkeys (Macaca mulatta) during growth and following experimental alteration. This method should be of general use for other researchers studying biomechanics of primate and mammalian masticatory systems and for those who use noniuman primates as models for investigating the effects on masticatory muscles of treatment protocols in clinical dentistry. First, the bite force device is described. Second, an account of our stimulation procedure is given. Finally, data from several tests with our procedures are reported.

\section{BITE FORCE DEVICE}

The bite force transducer (Fig. 1) consists of two steel beams mounted opposite one another on an aluminum handle. This transducer is similar in design to some other bite force devices (Garner and Kotwal, 1973; Helkimo et al., 1977; Linderholm and Wennström, 1970; Robins, 1977) but differs in the configuration of the attached strain gages. Two $350 \Omega$ single element strain gages (Micromeasurements EA-06-062AQ-350) are oriented along the inner surface of each beam and are connected in a full bridge configuration (Fig. 1). The advantage of this type of configuration over the half bridge configuration with one gage on each beam, which is frequently used in such transducers, is that each beam functions as a differential strain beam. The voltage output is therefore proportional to the dif- 

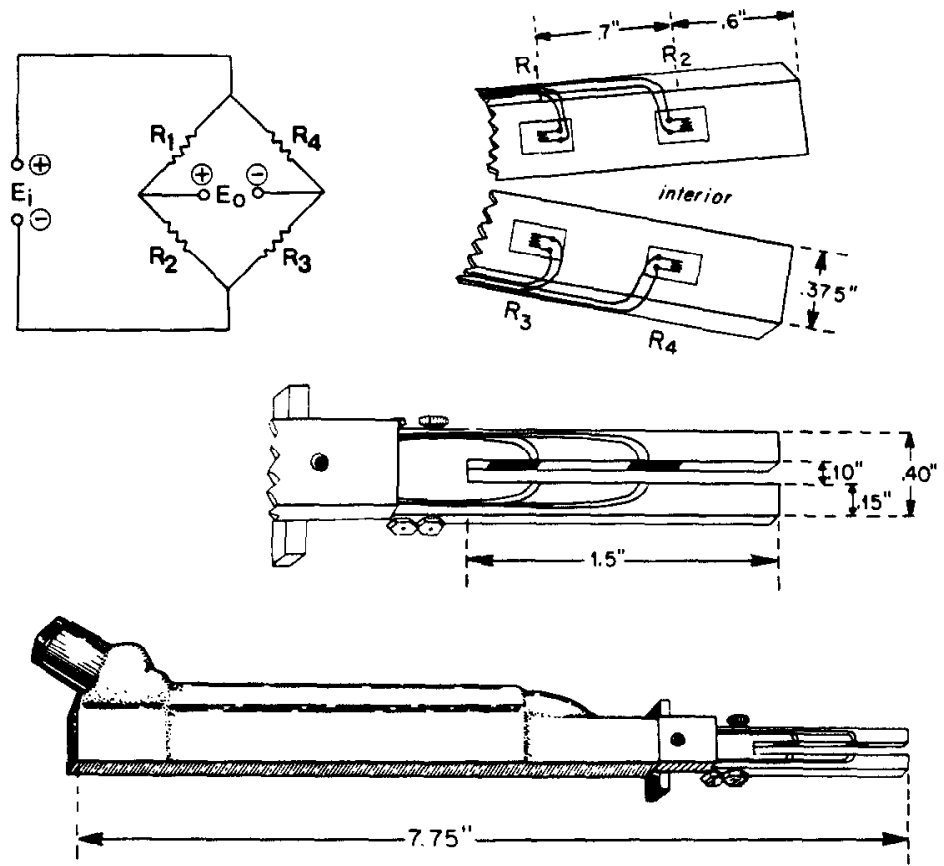

Fig. 1. Bite force transducer. Bottom: illustration of the complete device. Middle: enlargement of the distal end of the device showing dimensions. Top right: inner surface of the beams showing the arrangement of the strain gages. Top left: Wheatstone bridge illustrating proper configuration of the four strain gages. Note that all dimensions are in imperical units. These are converted to metric units for calculations elsewhere in this paper as follows: width of base of beams $=0.9525 \mathrm{~cm}$; height of beams $=0.381 \mathrm{~cm}$; distance between the distal and proximal strain gages $=1.778 \mathrm{~cm}$.

ference in strain between the two gages on the upper beam plus the difference from the lower beam. Thus, the position of the bite force on the transducer can vary as long as it is perpendicular to the long axis of the transducer and is distal to the most distal gage. This consideration is important as measurement error due to inconsistancy in the position of biting on the device is reduced.

Calibration of the bite force transducer reveals similar theoretical and measured results (Fig. 2). The relationship between the theoretical voltage output and applied bite force can easily be determined. Given the gage configuration in Fig. 1 ,

$$
E_{o} / E=\left(G\left(\varepsilon_{1}-\varepsilon_{2}\right)\right) / 2
$$

where $E_{0}$ is the voltage output from the Wheatstone bridge; $E$ is the excitation voltage; $G$ is the gage factor; $\varepsilon_{1}$ is the strain at the distal gages; and $\varepsilon_{2}$ is the strain at the proximal gages. Another definition of strain (Hylander, 1979) is

$$
\varepsilon=(M k) /(I Y)
$$

where $M$ is the magnitude of the bending moment and is equal to the product of the applied load $(P)$ and the length of the moment $\operatorname{arm}(d) ; k$ is the distance from the bending axis of neutrality to the section of the beam being studied, which in this case is one half the height of each beam $(h) ; I$ is the second moment of inertia of the cross-section of the beam, which equals $1 / 12$ of the product of the width of the base of the beams $(b)$
LINEAR RESPONSE OF BITE FORCE TRANSDUCER

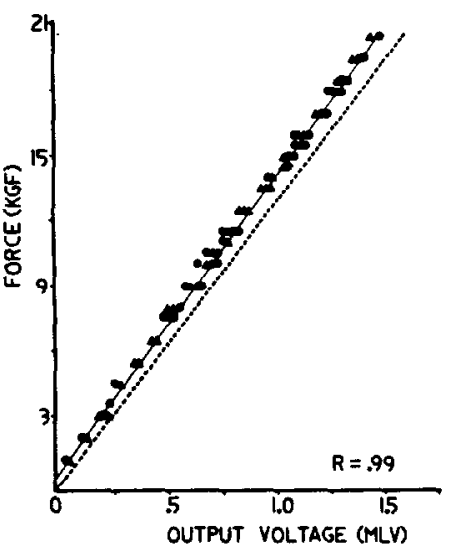

Fig. 2. Linear response of the bite force transducer. Circles indicate single observations; triangles indicate multiple observations. The solid line is the least squares regression line for applied force versus output voltage. The dashed line is the theoretical response of the bite force transducer.

multiplied by the cube of the height $(h)$; and $Y$ equals the modulus of elasticity. Combining equation (2) with the above definitions demonstrates that

$$
\varepsilon_{1}-\varepsilon_{2}=(6 P \Delta d) /\left(b h^{2} Y\right)
$$

where $\Delta d$ is the distance from the bite point to the distal 
gage minus the distance from the bite point to the proximal gage, or simply, the distance between the two gages on either beam. Substituting and rearranging equations (1) and (3) reveals that

$$
E_{o} / P=(3 E G \Delta d) /\left(b h^{2} Y\right)
$$

If the dimensions of the beams and gage positions given in Fig. 1 are used for $b, h$ and $\Delta d ; E$ is $2 \mathrm{~V}, G$ is 2.105 and $Y$ is $21.1 \times 10^{5} \mathrm{kgf} \mathrm{cm}^{-2}\left(30 \times 10^{6} \mathrm{psi}\right)$, then $E_{o} / P$ or the theoretical voltage output per kilogram force is $77 \mu \mathrm{V} \mathrm{kgf}^{-1}$.

The actual response of the bite force transducer was measured by suspending weights from the upper beam while the lower beam rested against a stable surface as illustrated in Fig. 3. The suspended weights were of 36 different magnitudes varying between 0.84 and $20.58 \mathrm{~kg}$. The instrument was initially calibrated on six different occasions. Actual response was linear with an output of $72 \mu \mathrm{V} \mathrm{kgf}^{-1}$ for strain gage excitation voltages of $2 \mathrm{~V}$. These measurements were made with a Vishay 2100 system strain gage conditioner and amplifier, and a Tektronix 5113 dual beam storage oscilloscope. Note that the measured response is very similar to the theoretical response, which is predicted above from the dimensions and material properties of

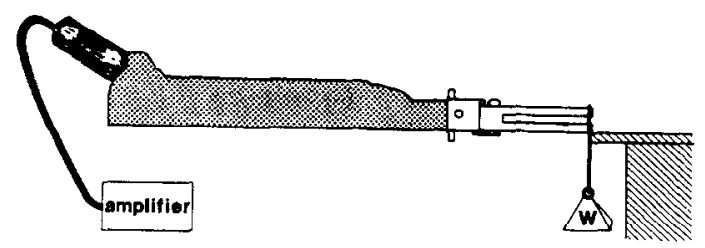

Fig. 3. Method of calibrating the bite force transducer. A weight is suspended from the upper beam of the bite force transducer while the lower beam is placed on a supporting surface. the transducer itself, and is illustrated in Fig. 2 by the dotted line.

Maximum response of the bite force transducer was not measured but was calculated at $128 \mathrm{kgf}$ from equations given by Beer and Johnston (1981, p. 399). This is the force theoretically necessary to cause the two steel beams to touch.

\section{STIMULATION PROCEDURE}

Bite force recordings from restrained alert monkeys may not always be useful in assessing growth and treatment effects on maximal strength of masticatory muscles for reasons discussed above. Therefore, a method of muscle stimulation was devised that approximated unilateral coordinated maximal firing of all masticatory muscles. Monkeys were anesthetized with a combination of ketamine $\mathrm{HCl}\left(7-15 \mathrm{mg} \mathrm{kg}^{-1}\right)$ and Rompun (Xylazine; 1-2 mg/kg). Two Grass unipolar needle electrodes were inserted into the masseter muscle through the skin as depicted in the left portion of Fig. 4. The muscle was stimulated and fused tetanus was obtained with $0.8 \mathrm{~ms}$ bursts at greater than $60 \mathrm{~Hz}$.

The chief problem with this approach was that the electrical stimulus was highly diffuse and produced contraction of masseter, temporalis and other orofacial muscles as determined by observation and palpation. However, this problem was not limiting when we considered that the range of muscle contraction was related to the applied voltage and electrode placement. We found that the response to varying voltage and electrode placement in 10 animals was similar. An example for one animal is illustrated in Fig. 4. The left illustration shows the bite force response for a variety of stimulation voltages with the electrodes in the masseter muscle alone. Note that a force plateau is
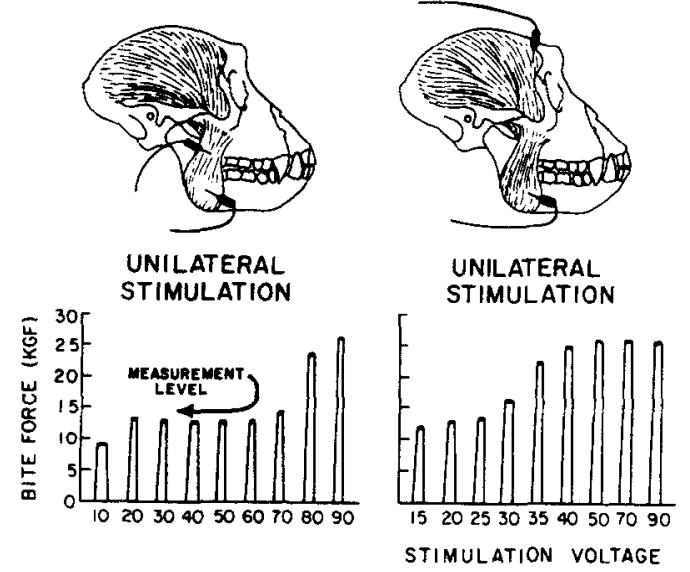
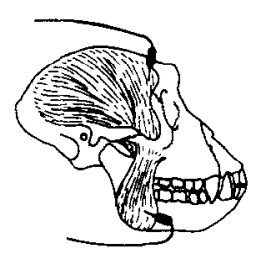

UNILATERAL

STIMULATION VOLTAGE

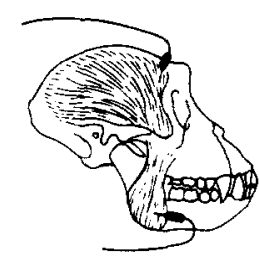

BILATERAL STIMULATION

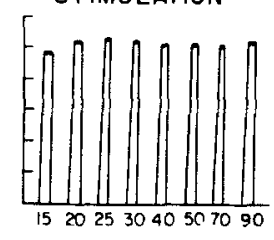

Fig. 4. Bite force response to variations in applied stimulation voltage and electrode placement. Left figures illustrate placement of stimulating electrodes in the masseter muscle alone (top) and the corresponding changes in bite force with increasing stimulation voltage when the electrodes are in this position (bottom). The measurement level is a plateau of response that approximates maximum unilateral bite force. The bottom middle figure shows the change in bite force with increasing stimulation for electrodes placed unilaterally in the masseter and tempoialis muscles (top middle). The response in the right bottom figure results from bilateral stimulation of the temporalis and masseter muscles (top right). 
achieved between stimulations of 20 and $60 \mathrm{~V}$. In thecentral illustration, which depicts bite force response with electrodes positioned unilaterally in the temporalis and masseter muscles, the plateau level is found only at lower stimulation voltages. Voltages that produce bite forces greater than this plateau were thought to stimulate contralateral masticatory muscles. If contralateral muscles were palpated during stimulation, they could be felt to contract as the higher voltages were reached. At higher voltages, a second plateau was achieved that cannot be exceeded by additional stimulation. This plateau was also seen at lower stimulation voltages, as shown in the right illustration of Fig. 4, when electrodes were placed bilaterally in both the temporalis and masseter muscles. The fact that this second bite force plateau was approximately twice that of the first and that contralateral muscle contraction could not be palpated at lower plateau voltage levels led to the deduction that bite force at the lower level was maximal unilateral bite force. In our experiments, this plateau could easily be found in all monkeys by taking bite force readings while the stimulation voltage was varied between 10 and $50 \mathrm{~V}$ and the electrodes were placed unilaterally in the masseter muscle.

The hypothesis that stimulation at the low plateau level resulted in unilateral muscle force without involvement of contralateral musculature was tested further by conducting two strain gage experiments. A single element strain gage (Micromeasurements CEA06-032UW-120) in one monkey was bonded near the lower border of the right mandibular corpus and a stacked delta rosette (Micromeasurements EA-06$015 Y D-120$ ) was bonded in the same location in another monkey using methods similar to Hylander (1977). The expectation was that higher strain levels would be evident during incisor biting when the muscles were stimulated in the lower plateau range and the gage was on the stimulated side. However, strain levels were expected to be negligible when the muscles contralateral to the gage site were stimulated. As expected, negligible strain was found when muscles were stimulated on the side contralateral from the gage site indicating no bone strain or muscle force production (Fig. 5). However, strain levels were higher when muscle stimulation was on the same side as the gage. Further stimulations with higher voltages and electrodes inserted in the masseter muscle alone in addition to other more dispersed electrode placements resulted in higher strain levels in the mandible contralateral to the muscle stimulation indicating that the masticatory muscles on both sides were involved in producing the bite force.

\section{TESTS OF THE SYSTEM}

Another consideration in the use of the bite force protocol was the effect of nonorthal biting on the transducer. The directions of loads in orthal biting is illustrated in the upper illustration of Fig. 6 by the arrows $P_{0}$. An example of the direction of loads in
STRAIN GAGE EXPERIMENT Biting of Incisors
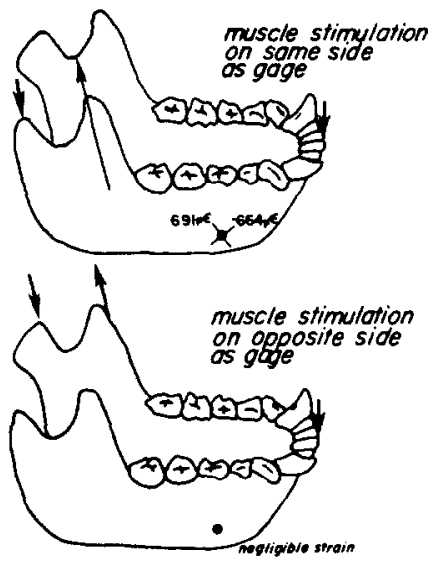

Fig. 5. Results of experiment examining bone strain along the lower border of the mandibular corpus during unilateral muscle stimulation to test response of contralateral masticatory muscles. Hypothesized directions of muscle force and temporomandibular joint reaction force are indicated by arrows. A rosette strain gage was positioned at the location indicated in both upper and lower figures. The upper figure shows values of over 600 compressive and tensile microstrain in one example of incisal biting when muscle stimulation was on the same side as the strain gage. When muscle stimulation was on the opposite side as the gage (bottom figure), negligible strain along the lower border of the mandibular corpus suggested a lack of contralateral muscle involvement in producing the bite force.

Deviation from Normal in Bite Force Direction
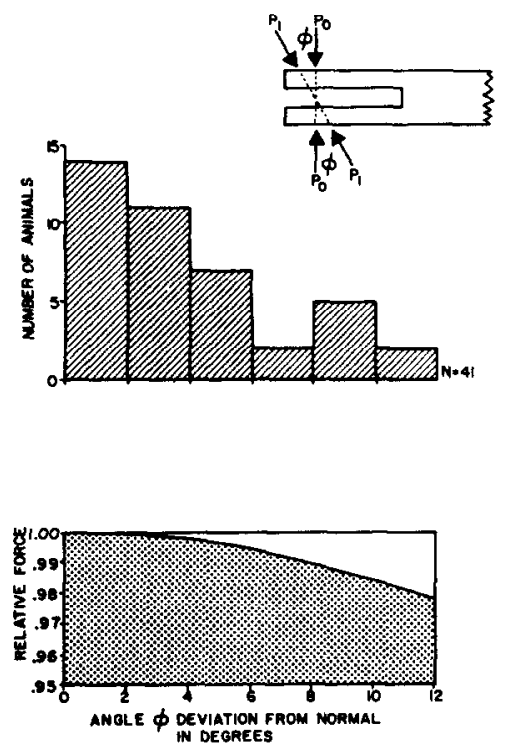

Fig. 6. Effect of deviation from orthal biting in the response of the bite force transducer. The upper drawing illustrates the direction of normal force, $P_{0}$, on the bite force transducer, a non-normal force, $P_{1}$, and the angle, $\phi$, between them. The middle shows the distribution of angle $\phi$ in a sample of 41 rhesus monkeys. These deviations from normal result in a maximum decrease of $2 \%$ in bite force (bottom drawing). Note that the $x$ axis scale for the middle and bottom drawings is identical and is given beneath the bottom drawing. 
nonorthal biting is illustrated by arrows $P_{1}$. The axial components of load $P_{1}$ would result in equal strains on the lower beam and the upper beam that are opposite in sign. The magnitude and sign of these strains would depend on the magnitude of the load and the direction of $P_{1}$. However, given the configuration of the strain gages as illustrated in Fig. 1, the effects of the axial strains on the upper and lower beams would cancel. Thus, the measured load would vary as a product of the actual load and the cosine of the angle $(\phi)$ between the direction of the applied load $\left(P_{1}\right)$ and the imagined perpendicular $\left(P_{0}\right)$. To test the actual deviation from perpendicular in loads applied to the bite force transducer during muscle stimulation, lateral cephalograms were taken of 41 monkeys during stimulated incisal clenching. The cephalograms were traced and the angle $(\phi)$ was measured between a perpendicular to the bite force transducer and a line connecting the contact points on the transducer of the upper and lower incisors. The results (middle illustration of Fig. 6) demonstrate that in the majority of animals, angle $\phi$ was $4^{\circ}$ or less with a maximum value of $12^{\circ}$. The maximum deviation from the perpendicular results in a measured load decrease of only $2 \%$ (bottom illustration of Fig. 6). Clearly, deviations from normal in bite force direction do not add greatly to measurement error.

As a final test of the reproducibility of results from the transducer and stimulation procedure, unilateral hiting force was measured at the incisors in 43 monkeys. These measurements were then repeated on all animals within one month. A histogram of the differences between the two measurements (Fig. 7) shows that the majority of animals (28/43) measured within $1 \mathrm{kgf}$ of the initial bite force with only 2

REPEATABILITY OF BITE FORCE MEASUREMENTS

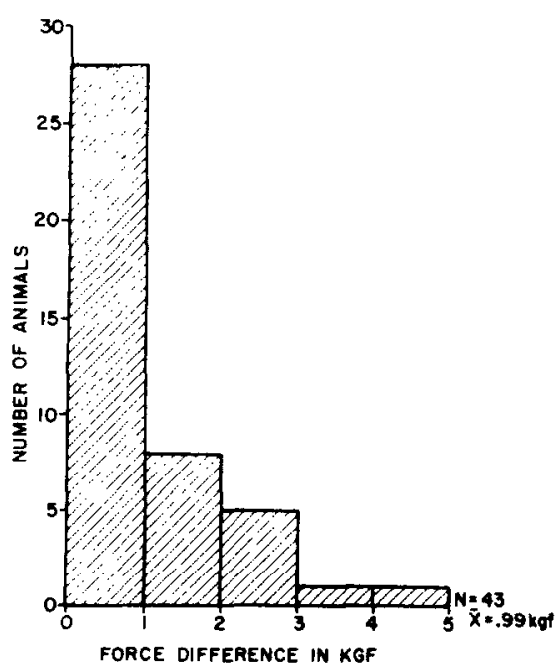

Fig. 7. Repeatability of bite force measurements. This difference in kgf between two bite force readings taken approximately one month apart in 43 monkeys shows a mean difference of $0.99 \mathrm{kgf}$. individuals showing differences of greater than $3 \mathrm{kgf}$. This amount of error is small relative to the total range (1-50 kgf) of macaque bite force values.

In summary, the bite force transducer described in this study accurately and predictably measures orthal loads exerted upon it. A specific configuration of four strain gages causes the device to function as two differential strain beams allowing identical readings even if the position of the bite point on the transducer varies. Our stimulation procedure produces bite force that approximates maximum unilateral isometric force of the masticatory muscles as mediated by the jaw lever system without inhibition by periodontal feedback. We conclude that our method of bite force measurement is useful and reliable for long- and short-term studies of the changes due to growth and experimental alteration of the physiological properties of the muscles of mastication.

Acknowledgements-We are indebted to Dr. F. Gaynor Evans for reading and commenting on this manuscript and to $\mathrm{Mr}$. M. D. Fox for machining several versions of the bite force transducer. This research was supported by NIH grants DE03610, DE05232, and DE05271.

\section{REFERENCES}

Atkinson, H. F. and Ralph, W. J. (1973) Tooth loss and biting force in man. J. dent. Res. 52, 225-228.

Beer, F. P. and Johnston, E. R. Jr. (1981) Mechanics of Materials. McGraw-Hill, New York.

Black, G. B. (1895) The force exerted in the closure of the jaws. Dent. Cosmos 37, $469-484$.

Boos, R. H. (1940) Intermaxillary relation established by biting power. J. Am. dent. Ass. 27, 1192-1199.

Boucher, L. J., Zwemer, T. J. and Pflughoeft, F. (1959) Can biting force be used as a criterion for registering vertical dimension? J. prosth. Dent. 9, 594-599.

Brekhus, P. J., Armstrong, W. D. and Simon, W. J. (1941) Stimulation of the muscles of mastication. J. dent. Res. 20 , 87-92.

Brudevold, F. (1951) A basic study of the chewing forces of a denture wearer. J. Am. dent. Ass. 43, 45-51.

DeBoever, J. A., McCall, W. D., Holden, S. and Ash, M. M. Jr. (1978) Functional occlusal forces: an investigation by telemetry. J. prosth. Dent. 40, 326-333.

Dechow, P. C. and Carlson, D. S. (1982a) Bite force and gape in rhesus macaques. Am. J. phys. Anthropol. 57, 179.

Dechow, P. C. and Carlson, D. S. (1982b) Development of masticatory muscle force in macaques. J. dent. Res. 61, 211.

Dechow, P. C., Carlson, D. S., LaBanc, J. P. and Epker, B. N. (1983) Changes in bite force by masticatory muscle repositioning in Macaca nemestrina. Am. J. phys. Anthropol. 60, 187-188.

DeHernandez, C. J. and Bodine, R. L. (1969) Mastication strength with implant dentures as compared with softtissue-borne dentures. J. prosth. Dent. 22, 479-486.

Fields, H. W., Proffit, W. R., Moray, L. J. and Case, J. C. (1982) Evaluation of vertical occlusal force in normal and long face children. J. dent. Res. 61, 342.

Frechette, A. R. (1955) Masticatory forces associated with use of various types of teeth. J. prosth. Dent. 5, 252-267.

Garner, L. D. and Kotwal, N. S. (1973) Correlation study of incisive biting forces with age, sex and anterior occlusion. J. dent. Res. 52, 698-702.

Garrett, F. A., Angelone, L. and Allen, W. I. (1969) The effect of bite opening, bite pressure and malocclusion on the 
electrical response of the masseter muscles. Am. J. Orthod. 50, 435-444:

Helkimo, E., Carlsson, G. E. and Carmeli, Y. (1975) Bite force in patients with functional disturbances of the masticatory system. J. Oral Rehab. 2, 397-406.

Helkimo, E., Carlsson, G. E. and Helkimo, M. (1977) Bite force and state of dentition. Acta odont. scand. 35, 297-303.

Helkimo, E. and Ingervall, B. (1978) Bite force and functional state of the masticatory system in young men. Swed. dent. J. 2, 167-175.

Howell, A. H. and Brudevold, F. (1950) Vertical forces used during chewing of food. J. dent. Res. 29, 133-136.

Hylander, W. L. (1977) In vivo bone strain in the mandible of Galago crassicaudatus. Am. J. phys. Anthropol. 46, 309-326.

Hylander, W. L. (1979) Mandibular function in Galago crassicaudatus and Macaca fascicularis: an in vivo approach to stress analysis of the mandible. J. Morph. 159, 253-296.

Johnson, A. L. and Hatfield, H. K. (1917) A study of the relation of dental conditions, biting force and the handgrip. Dent. Cosmos 59, 599-609.

Linderholm, H., Lindqvist, B., Ringqvist, M. and Wennström. (1971) Isometric bite force in children and its relation to body build and general muscle force. Acta odont. scand. 29, 563-568.

Linderholm, H. and Wennström, A. (1970) Isometric bite force and its relation to general muscle force and body build. Acta odont. scand. 28, 679-689.

Lindqvist, B. and Ringqvist, M. (1973) Bite force in children with bruxism. Acta odont. scand. 31, 255-259.

Manly, R. S. and Vinton, P. (1951) A survey of the chewing ability of denture wearers. J. dent. Res. 30, 314-321.

Manns, A., Miralles, R. and Palazzi, C. (1979) EMG, bite force, and elongation of the masseter muscle under isometric voluntary contractions and variations of vertical dimension. J. prosth. Dent. 42, 674-682.

Marklund, G. and Wennström, A. (1972) A pilot study concerning the relation between manifest anxiety and bite force. Suensk. Tandläk Förb. Tidn. 65, 107-110.

Molin, C. (1972) Vertical isometric muscle forces of the mandible, a comparative study of subjects with and without manifest mandibular pain dysfunction syndrome. Acta. odont. scand. 30, 485-499.

Nordstrom, S. H. and Yemm, R. (1974) The relationship between jaw position and isometric active tension produced by direct stimulation of the rat masseter muscle. Archs oral Biol. 19, 353-359.

Nyquist, G. and Owall, B. (1968) Masticatory load registrations during function, a methodological study. Odont. Revy 19, 45-54.
Palla, S. and Ash, M. M. Jr. (1981) Effect of bite force on the power spectrum of the surface electromyogram of human jaw muscles. Archs oral Biol. 26, 287-295.

Proffit, W. R., Fields, H. W. and Nixon, W. L. (1982) Evaluation of vertical occlusal forces in normal and long face adults. J. dent. Res. 61, 342 .

Pruim, G. J. (1979) Asymmetries of bilateral static bite forces in different locations on the human mandible. J. dent. Res. 58, 1685-1687.

Pruim, G. J., DeJongh, H. J. and TenBosch, J. J. (1980) Forces acting on the mandible during bilateral static bite at different bite force levels. J. Biomechanics 13, 755-763.

Ringqvist, M. (1973a) Fibre sizes of human masseter muscle in relation to bite force. J. Neurosci. 19, 297-305.

Ringqvist, M. (1973b) Isometric bite force and its relation to dimensions of the facial skeleton. Acta odont. scand. 31, 35-42.

Robins, M. W. (1977) Biting loads generated by the laboratory rat. Archs oral Biol. 22, 43-47.

Tarbet, W. J., Silverman, G. and Schmidt, N. F. (1981) Maximum incisal biting force in denture wearers as influenced by adequacy of denture-bearing tissues and use of an adhesive. J. dent. Res. 60, 115-119.

Thexton, A. J. and Hiiemae, K. M. (1975) The twitchcontraction characteristics of opossum jaw musculature. Archs oral Biol. 20, 743-748.

Throckmorton, G. S., Finn, R. A. and Bell, W. H. (1980) Biomechanics of differences in lower facial height. $A m$. J. Orthod. 77, 410-420.

Tueller, V. M. (1969) The relationship between the vertical dimension of occlusion and forces generated by closing muscles of mastication. J. prosth. Dent. 22, 284-288.

Wennström, A. (1971) Psychophysical investigation of bite force, parts I and II. Svensk. Tandläk Förb. Tidn. 64, 807-819, 821-827.

Wennström, A. (1972) Psychophysical investigation of bite force, parts III and IV. Svensk. Tandläk Förb. Tidn. 65, $177-184,185-190$.

Worner, H. K. (1939) Gnathodynamics, the measurement of biting forces with a new design of gnathodynamometer Aust. J. Dent. 43, 381-393.

Worner, H. K. and Anderson, M. N. (1944) Biting force measurements on children. Aust. J. Dent. 48, 1-12.

Yurkstas, A. (1953) The effect of masticatory exercise on the maximum force tolerance of individual teeth. J. dent. Res. 32, 322-327.

Yurkstas, A. and Curby, W. (1953) Force analysis of prosthetic appliances during function. J. prosth. Dent. 3, 82-87. 